Supporting Information for:

\title{
Shaping Block Copolymer Microparticles by pH-Responsive Core-Cross-linked Polymeric Nanoparticles
}

Mengmeng Zhang, Zaiyan Hou, Huiying Wang, Lianbin Zhang, * Jiangping Xu*, and Jintao Zhu

State Key Lab of Materials Processing and Die \& Mould Technology and Key Lab of Material

Chemistry for Energy Conversion \& Storage (HUST) of Ministry of Education, School of Chemistry and Chemical Engineering, Huazhong University of Science and Technology (HUST),

Wuhan 430074, China

*Email: jiangpingxu@hust.edu.cn.

*Email: zhanglianbin@hust.edu.cn.

Number of pages: 9

Number of figures: 12

Number of tables: 1

Number of schemes: 0

\section{Contents}

1. DLS analysis of the hydrodynamic diameter of CNPs in water and DMF at different $\mathrm{pH}$ values.

2. Zeta potential of CNPs in deionized water.

3. TEM images of PS- $b$-PDMS microparticles prepared by solely using CTAB as surfactant at different $\mathrm{pH}$ values.

4. TEM images of PS- $b$-PDMS microparticles prepared by solely using CNPs as 
surfactant at different $\mathrm{pH}$ values.

5. Optical microscopy images showing the evaporation of emulsion droplets prepared by solely using CNPs as surfactant at different $\mathrm{pH}$ values.

6. TEM images of PS- $b$-PDMS microparticles prepared by combinedly using CTAB and CNPs as surfactant at different $\mathrm{pH}$ values.

7. The fraction of microparticle morphology obtained at different $\mathrm{pH}$ values.

8. TEM images of Janus pupa-like and onion-like microparticles after 4 months of storage.

9. Zeta potential measurement of PS- $b$-PDMS microparticles prepared by combinedly using CTAB and CNPs as surfactants at different $\mathrm{pH}$ values.

10. Optical microscopy images showing the evaporation of emulsion droplets prepared using non-cross-linked PS- $b$-P4VP as cosurfactant at different $\mathrm{pH}$ values.

11. TEM images of PS- $b$-PDMS microparticles formed at $\mathrm{pH} 5.8$ with varied weight fraction of CNPs.

12. TEM images of PS- $b$-PDMS microparticles prepared by solely using SDS as surfactant at different $\mathrm{pH}$ values.

13. Zeta potential measurement of PS- $b$-PDMS microparticles using SDS as the surfactant at $\mathrm{pH} 6.0$. 


\section{Supplementary Figures and table:}
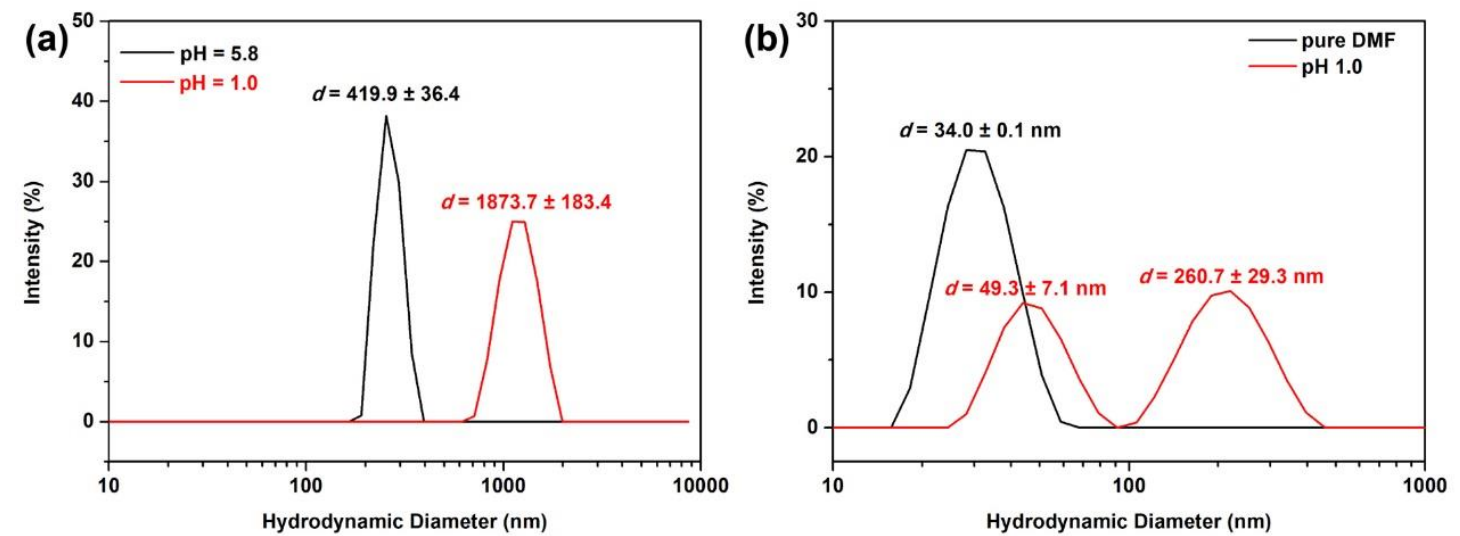

Figure S1. Dynamic light scattering analysis of the hydrodynamic diameter of CNPs in (a) water and (b) DMF at different $\mathrm{pH}$ values.

As the CNPs are insoluble in water due to the PS corona, they will aggregate in deionized water. It is very difficult to directly characterize the change of the size of a single CNP with the decrease of $\mathrm{pH}$ value in water. However, we measured the size change of the aggregates in water at different $\mathrm{pH}$ values by DLS. As shown in Figure S1a, at $\mathrm{pH} 5.8$, the diameter was $419.9 \pm 36.4 \mathrm{~nm}$. When the $\mathrm{pH}$ was reduced to 1.0, the diameter of CNPs was significantly increased to $1873.7 \pm 183.4 \mathrm{~nm}$.

Considering that water was not a good solvent for CNPs, we chose DMF, a good solvent of CNPs, for measuring the size change at different $\mathrm{pH}$ values. As shown in Figure S1b, the diameter of CNPs in DMF $(34.0 \pm 0.1 \mathrm{~nm})$ was very close to that in chloroform $(48.2 \pm 0.6 \mathrm{~nm})$. When the $\mathrm{pH}$ was reduced to 1.0 , the diameter of CNPs increased to $49.3 \pm 7.1 \mathrm{~nm}$ and $260.7 \pm 29.3 \mathrm{~nm}$.

These results indicate that the diameter of CNPs will increase when the $\mathrm{pH}$ decreases. 


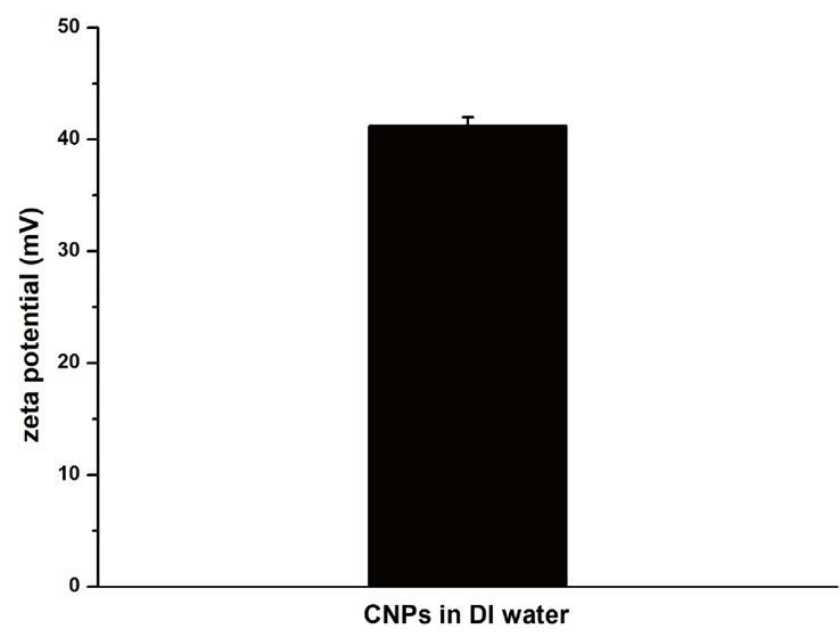

Figure S2. Zeta potential of CNPs in deionized (DI) water $(0.1 \mathrm{mg} / \mathrm{mL})$.

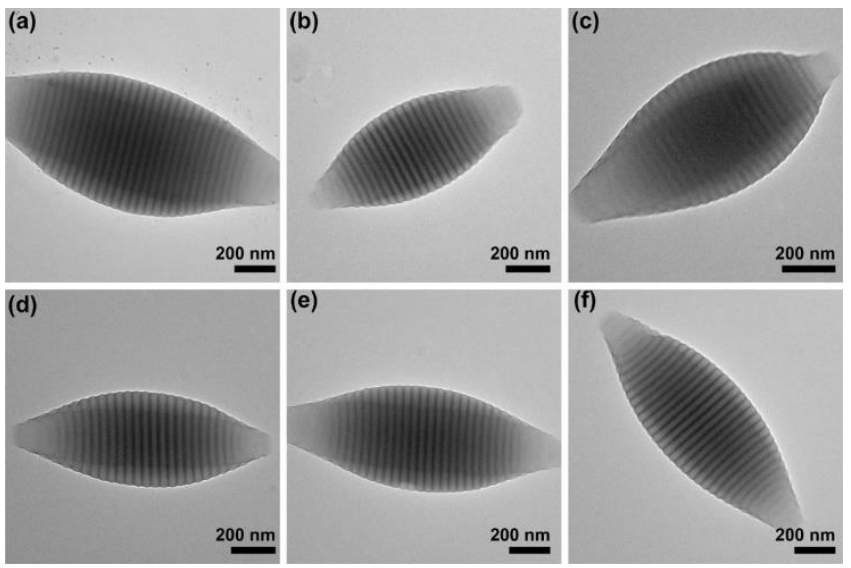

Figure S3. TEM images of PS- $b$-PDMS microparticles prepared by solely using CTAB as surfactant at different $\mathrm{pH}$ values: (a) $\mathrm{pH} 5.8$; (b) $\mathrm{pH} 4.8$; (c) $\mathrm{pH} 4.0$; (d) $\mathrm{pH} 3.0$; (e) $\mathrm{pH} 2.0$; and (f) $\mathrm{pH}$ 1.0. The concentration of CTAB was $3 \mathrm{mg} / \mathrm{mL}$. The change in $\mathrm{pH}$ values didn't affect the morphology of PS- $b$-PDMS microparticles. 


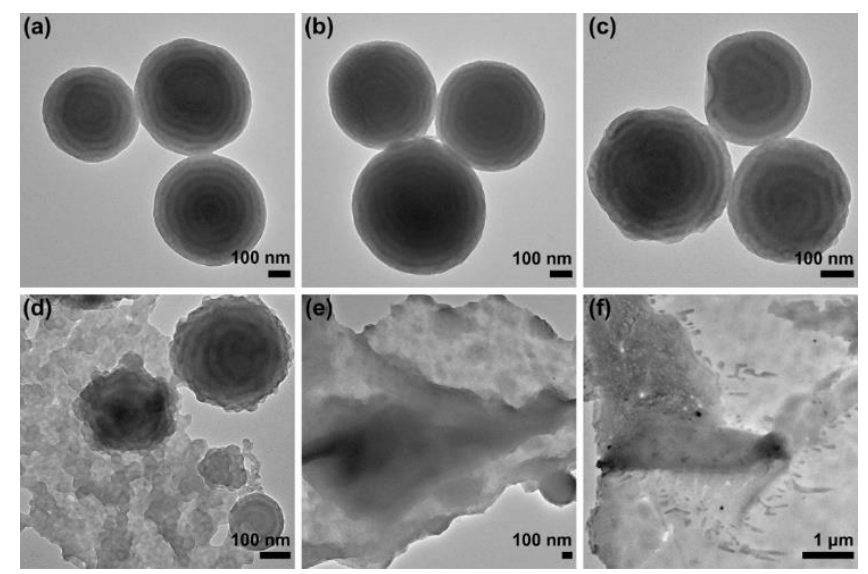

Figure S4. TEM images of PS- $b$-PDMS microparticles prepared by solely using CNPs as surfactant at different $\mathrm{pH}$ values: (a) $\mathrm{pH}$ 5.8; (b) $\mathrm{pH} 4.8$; (c) $\mathrm{pH} 4.0$; (d) $\mathrm{pH} 3.0$; (e) $\mathrm{pH} 2.0$; and (f) $\mathrm{pH} 1.0$. The weight fraction of CNPs was fixed at $20 \mathrm{wt} \%$.
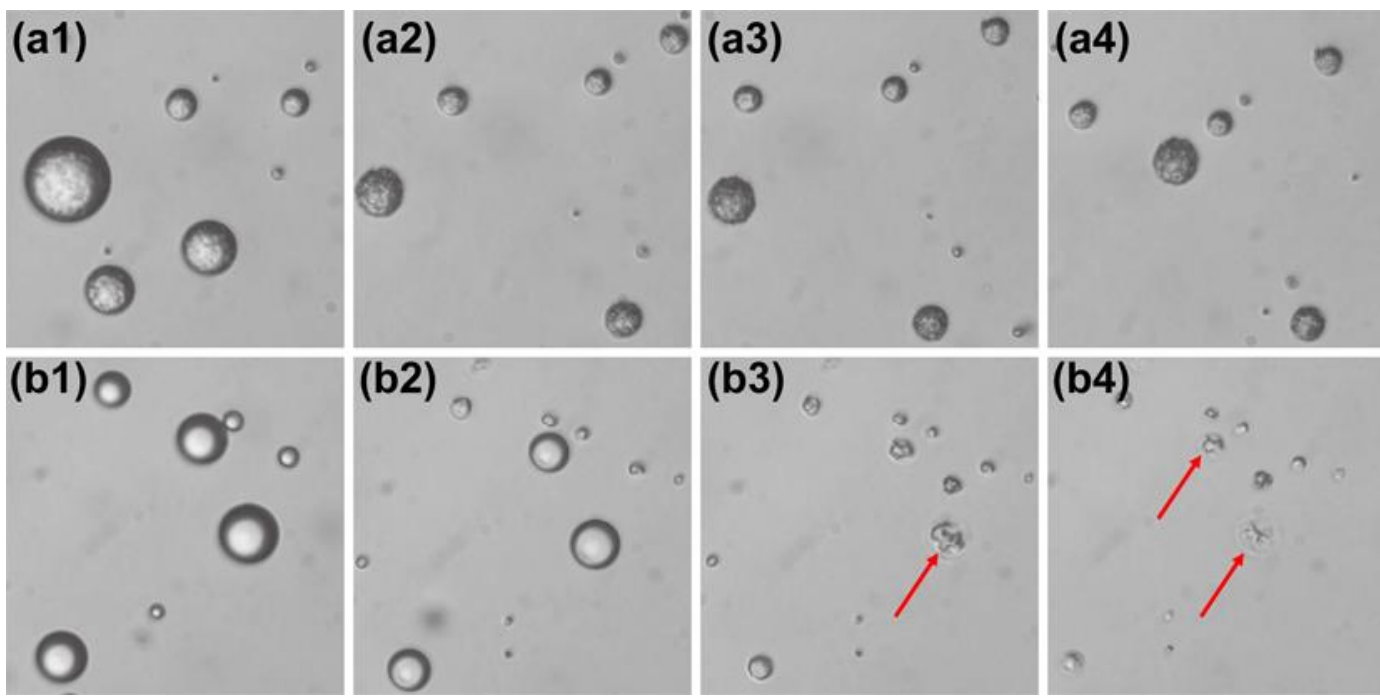

Figure S5. Optical microscopy images showing the evaporation of emulsion droplets prepared by solely using CNPs as surfactant at different $\mathrm{pH}$ values: (a1)-(a4) $\mathrm{pH}$ 5.8; (b1)-(b4) $\mathrm{pH}$ 1.0. Interfacial instability of emulsions was observed for sample at $\mathrm{pH}$ 1.0 , as indicated by the red arrows. 

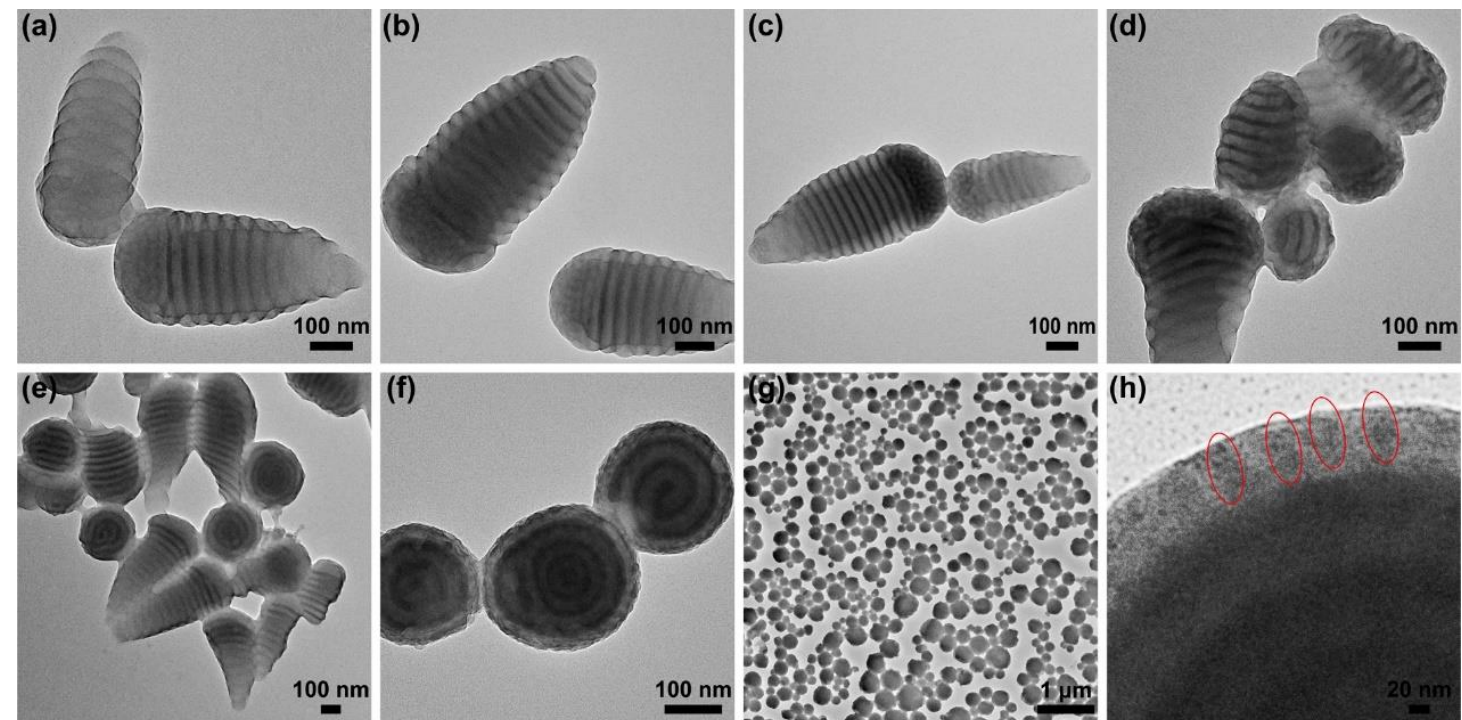

(h)

$00 \mathrm{~nm}$

Figure S6. TEM images of PS- $b$-PDMS microparticles prepared by combinedly using

CTAB and CNPs as surfactant at different pH values: (a) pH 5.8; (b) $\mathrm{pH} 4.8$; (c) pH 4.0;

(d) $\mathrm{pH} 3.0$; (e) $\mathrm{pH} 2.0$ and (f-h) $\mathrm{pH}$ 1.0. (g) Lower magnification TEM; (h) magnified

TEM image. The concentration of CTAB was $3 \mathrm{mg} / \mathrm{mL}$ and the weight fraction of CNPs was fixed at $20 \mathrm{wt} \%$.

Table S1. The fraction of microparticle morphology obtained at different $\mathrm{pH}$ values shown in Figure S6

\begin{tabular}{ccccccc}
\hline Morphology & pH 5.8 & pH 4.8 & pH 4.0 & pH 3.0 & pH 2.0 & pH 1.0 \\
\hline Janus pupa-like & $92 \%$ & $82 \%$ & $75 \%$ & $28 \%$ & $16 \%$ & $1 \%$ \\
Bud-like & $6 \%$ & $11 \%$ & $14 \%$ & $52 \%$ & $37 \%$ & $5 \%$ \\
Onion-like & $2 \%$ & $7 \%$ & $11 \%$ & $20 \%$ & $47 \%$ & $94 \%$ \\
\hline
\end{tabular}

a. The fraction was calculated based on TEM images for over 100 microparticles. 

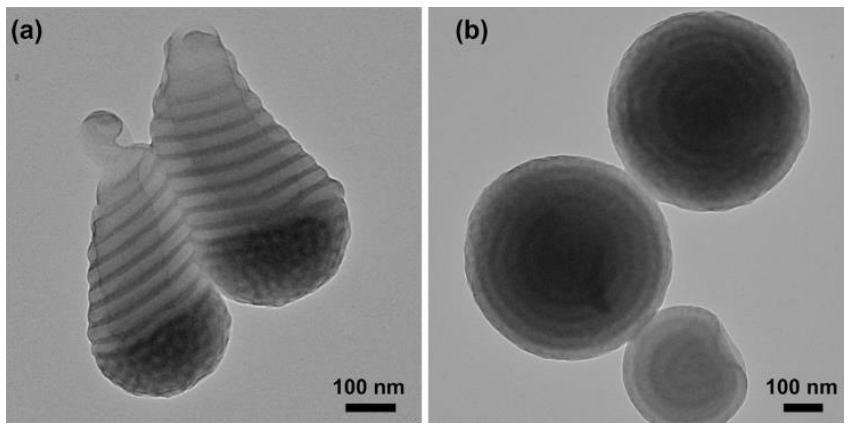

Figure S7. TEM images of (a) Janus pupa-like (pH 5.8) and (b) onion-like (pH 1.0) microparticles after 4 months of storage. These results indicate that the self-assembled particles have good stability.

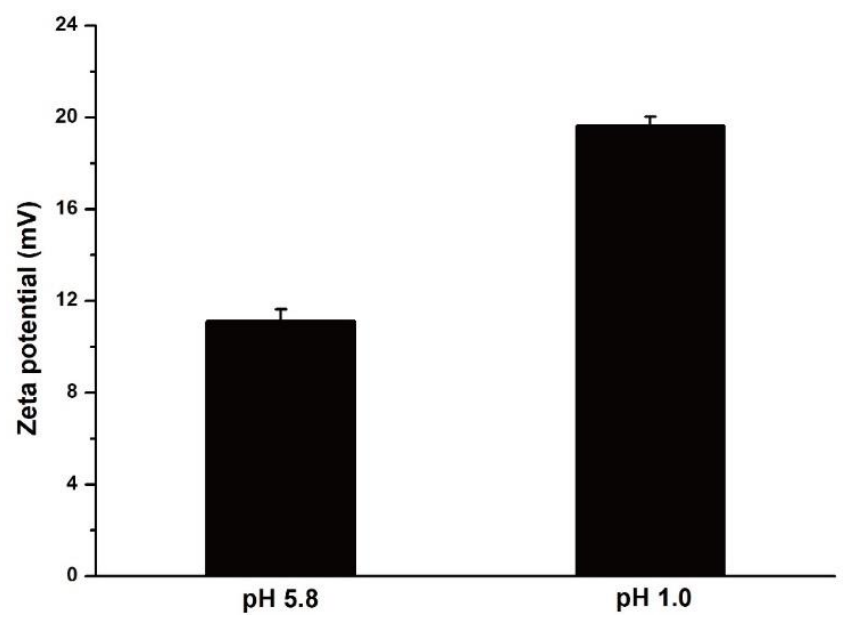

Figure S8. Zeta potential measurement of PS- $b$-PDMS microparticles prepared by combinedly using CTAB and CNPs as surfactants at different $\mathrm{pH}$ values. 


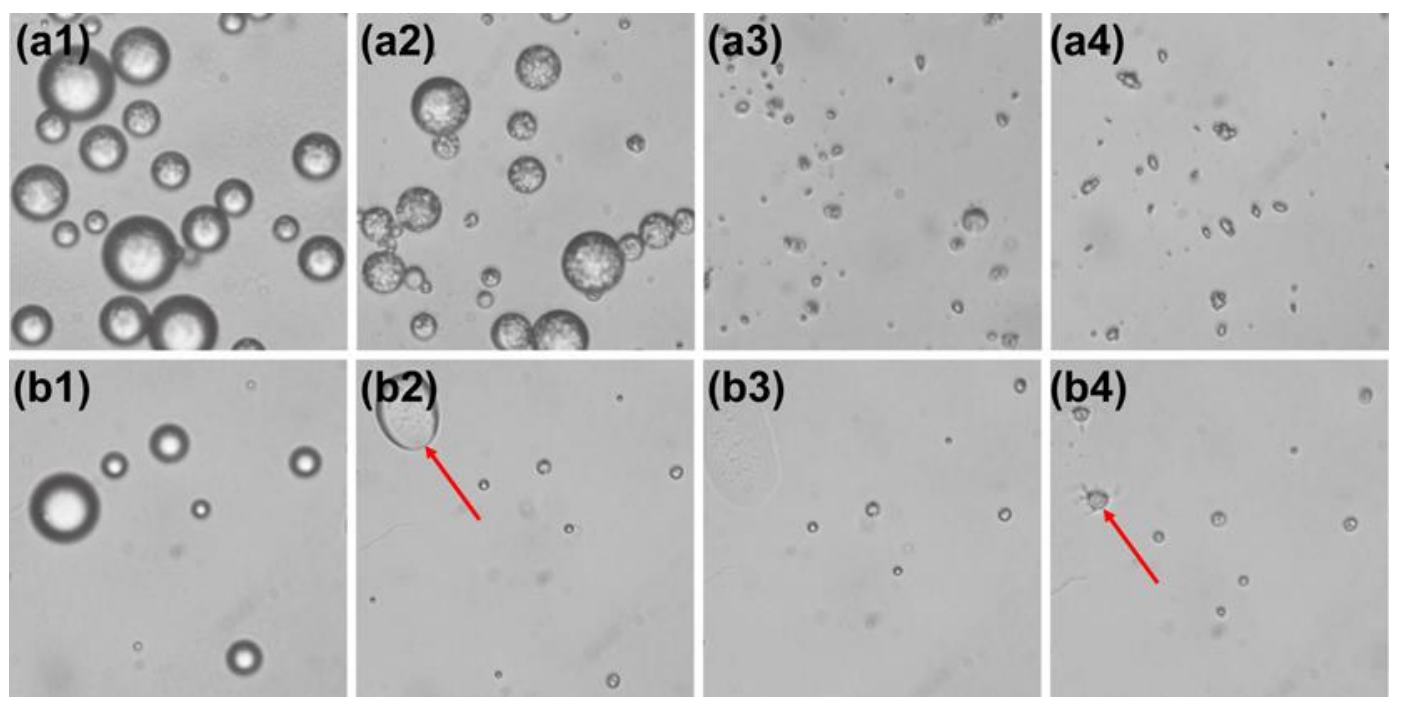

Figure S9. Optical microscopy images showing the evaporation of emulsion droplets prepared using non-cross-linked PS- $b$-P4VP as cosurfactant at different $\mathrm{pH}$ values: (a1)-(a4) $\mathrm{pH}$ 5.8; (b1)-(b4) $\mathrm{pH}$ 1.0. Interfacial instability of emulsions was observed for samples at $\mathrm{pH} 1.0$, as indicated by the red arrows.
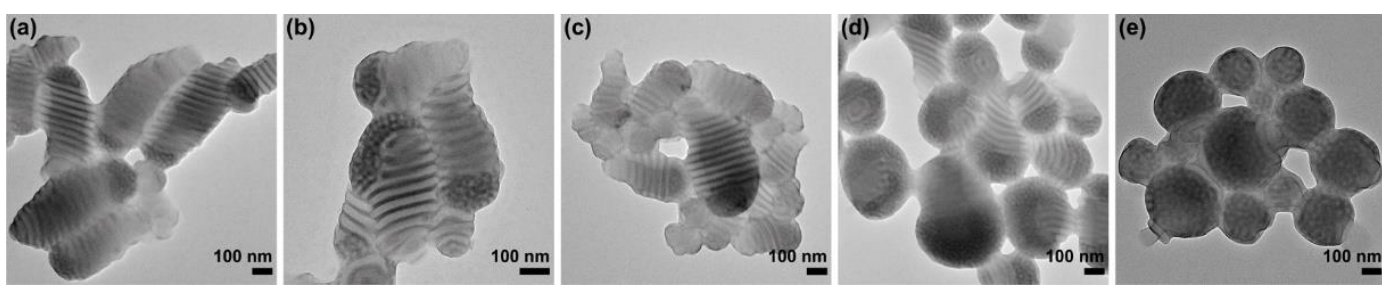

Figure S10. TEM images of PS- $b$-PDMS microparticles formed at $\mathrm{pH} 5.8$ with varied weight fraction $(\varphi)$ of CNPs, (a) $\varphi=10 \mathrm{wt} \%$, (b) $\varphi=20 \mathrm{wt} \%$, (c) $\varphi=30 \mathrm{wt} \%$, (d) $\varphi$ $=40 \mathrm{wt} \%$, and (e) $\varphi=70 \mathrm{wt} \%$. 

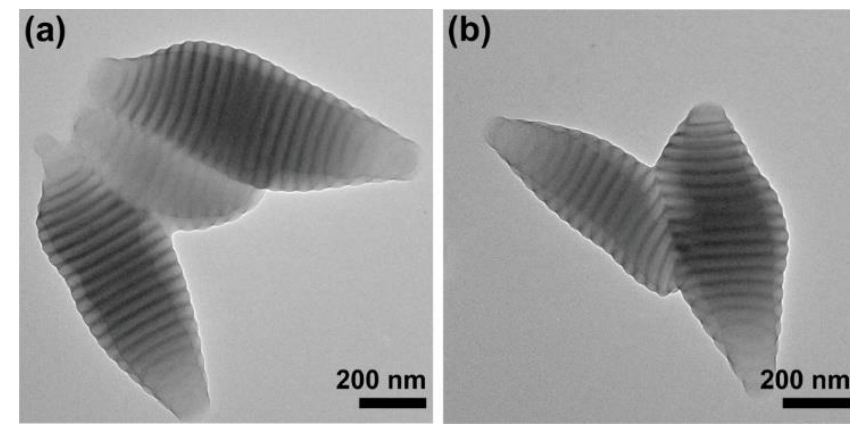

Figure S11. TEM images of PS- $b$-PDMS microparticles prepared by solely using SDS as surfactant at different $\mathrm{pH}$ values: (a) $\mathrm{pH} 6.0$; (b) $\mathrm{pH} 1.0$. The change in $\mathrm{pH}$ values didn't affect the morphology of PS- $b$-PDMS microparticles when SDS was applied as surfactant

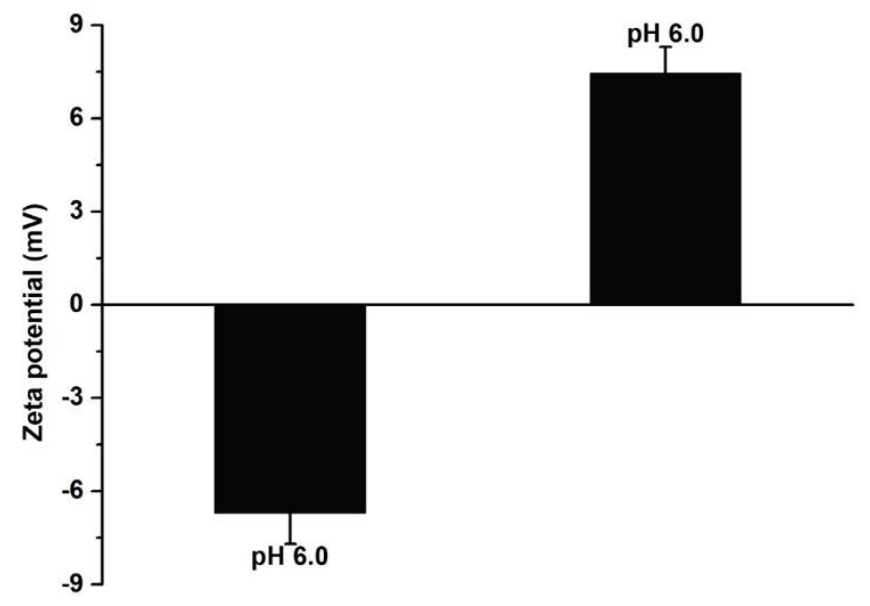

Figure S12. Zeta potential measurement of PS- $b$-PDMS microparticles using SDS as the surfactant at $\mathrm{pH}$ 6.0. The leftmost was PS- $b$-PDMS microparticles prepared by SDS. The right one was PS- $b$-PDMS microparticles prepared by SDS and CNPs. 